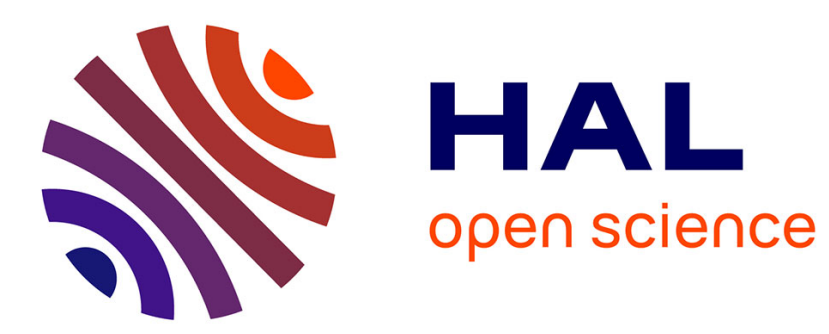

\title{
Integrated polymers (PVCi/PMATRIFE) microring resonators for low power tunable filters
}

\author{
Azar Maalouf, Michel Gadonna, Dominique Bosc, Isabelle Hardy
}

\section{To cite this version:}

Azar Maalouf, Michel Gadonna, Dominique Bosc, Isabelle Hardy. Integrated polymers (PVCi/PMATRIFE) microring resonators for low power tunable filters. Optics Communications, 2012, 285 (20), pp.4088-4091. 10.1016/j.optcom.2012.05.043 . hal-00723997

\section{HAL Id: hal-00723997 \\ https://hal.science/hal-00723997}

Submitted on 17 Aug 2012

HAL is a multi-disciplinary open access archive for the deposit and dissemination of scientific research documents, whether they are published or not. The documents may come from teaching and research institutions in France or abroad, or from public or private research centers.
L'archive ouverte pluridisciplinaire HAL, est destinée au dépôt et à la diffusion de documents scientifiques de niveau recherche, publiés ou non, émanant des établissements d'enseignement et de recherche français ou étrangers, des laboratoires publics ou privés. 
Author manuscript

\title{
Integrated polymers (PVCi / PMATRIFE) microring resonators for low power tunable filters.
}

\author{
Azar Maalouf ${ }^{1}$, Michel Gadonna ${ }^{2}$, Dominique Bosc ${ }^{1}$, Isabelle Hardy ${ }^{2}$ \\ 1 ) Université Européenne de Bretagne, CNRS, Laboratoire FOTON (UMR 6082), ENSSAT, 6, rue de \\ Kerampont, BP80518, 22305, Lannion,France \\ 2) Université Européenne de Bretagne, CNRS, Laboratoire FOTON (UMR 6082), Télécom Bretagne, 6, rue de \\ Kerampont, BP80518, 22305, Lannion,France
}

\begin{abstract}
In this paper we present optical and thermo-optical characterization results of integrated filters based on micro-ring resonators fabricated with a couple of polymers "PVCI/PMATRIFE". Their high index contrast (Dn $\square 0.15$ at the wavelength of $1550 \mathrm{~nm}$ ) allows to make small size waveguides with cross sections of $1.5 \square 1.5 \mathrm{~mm} 2$. The study of the impact of different gaps on the extinction ratio and FWHM (full width at half maximum) of filters leads to a better design. First experiments of thermal tenability of the microring filter using a thermo-electric cooler (TEC) are also reported giving a $5 \mathrm{~nm}$ shift of the dropped wavelength for a temperature change of $40 \mathrm{~K}$. The fabrication of gold electrodes on microrings is reported and the electrical power required for the tuning of the drop wavelength of $0.0055 \mathrm{~nm} / 1 \mathrm{~mW}$ show that with an optimized electrode design the consumption will be low.
\end{abstract}

Keywords-Polymer optical waveguides, Channel selective filter, Ring resonator, Thermo optic effect

\section{INTRODUCTION:}

In the domain of integrated optics, microring-resonators are proposed as a basic building block for the creation of more complex photonic functions. Using these blocks, it is possible to perform wavelength filtering applications. In other words these microring-resonators could be useful as multiplexers/demulti-plexers, switches, routers and modulators that are very important functions for processing digital information [1]. On the other hand, micro-resonators are increasingly used in the field of sensors, as they are sensitive to a refractive index change at some point of the microring [2,3].

For telecommunications, in order to provide the high band-width required to satisfy the increasing demand for applications as internet, high quality vide'o and multimedia; dense wavelength multiplexing and high bit rate modulation are used in optical networks. These technologies are moving more and more towards the end user. The DWDM grid standard from the International Telecommunication Union (ITU) is defined for a $100 \mathrm{GHz}(0.8$ $\mathrm{nm}$ ) spacing and below. For this reason, the optical functions must be a thermal devices.

The future network is expected to be a dynamic WDM network. For this application it is requested that the optical functions will be reconfigurable and tunable. This adaptation can be mainly done thermally or electrically [4-6]. In our study the aim is to achieve a thermally tunable filter, based on a full polymer microring resonator for access network using WDM technology. The requirement is an 8 channels filter with $100 \mathrm{GHz}$ spacing for $10 \mathrm{Gbit} / \mathrm{s}$ transmission rate. The microring fabrication process, the static measurements results and the transmission response data at $10 \mathrm{Gbit} / \mathrm{s}$ of the fabricated microring-resonators were presented in a previous paper [7].

In this paper, firstly we briefly remind the fabrication process of those microring resonators and we complete this section by detailing electrodes fabrication. In a second section, we present micro-resonators performances according to the gap between the ring and the waveguide. Finally, in last section, we report thermo- optical 
results.

\section{Micro-ring technologies and properties}

Upper and lower cladding are performed with PMATRIFE (Poly(2,2,2 MethAcrylate of TRIFluoro-Ethyle $))(\mathrm{n}=$ 1.409 at $\lambda=1550 \mathrm{~nm})$. The core is achieved with PVCi poly(Vinyl Cinnamate) $(\mathrm{n}=1.555$ at $\lambda=1550 \mathrm{~nm})$. This polymer was irradiated by UV for mechanical stabilization.

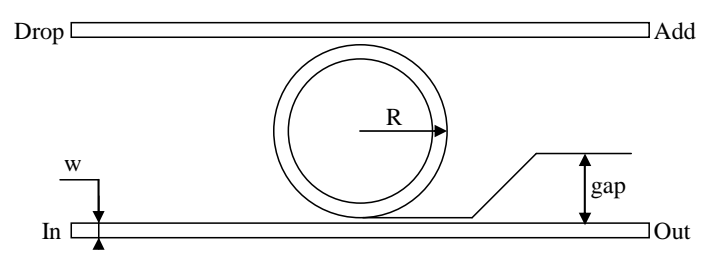

Figure 1: Microring resonator filter shape.

The filter shape consists of a microring coupled to two straight bus waveguides on either side as show on Figure 1. Optical simulations were carried out to define the microring filter design. The main input parameters for the design are: the system requirements: the WDM channel spacing and number, the inter channel crosstalk, the transmission losses. From this we deduce the Free Spectral Range (FSR), the finesse of the filter and with the material characteristics including the refractive index contrast $(\Delta n=0.15$ in our case) between the core and the cladding materials the better microresonators design could be found.

The first critical parameter, the microring radius, is defined as a trade-off between FSR, larger FSR correspond to lower ring radius, and optical losses, as they increase with decreasing of bending radius. The waveguide size calculated from the index contrast to have a mode confinement level adapted for the required coupling ratio was found as $1.5 \times 1.5 \mu \mathrm{m}^{2}$. With the effective index of this waveguide (around 1.49) the minimum bend radius allows defining a ring radius, $\mathrm{R}$, of $120 \mu \mathrm{m}$, giving a FSR of $2.04 \mathrm{~nm}$. The last and critical fabrication parameter is the gap between the guides and the ring, this parameter defines the filter bandwidth and the quality factor (or finesse). On the mask, the gap varies from $1 \mu \mathrm{m}$ to $0.5 \mu \mathrm{m}$, giving a theoretical finesse between 10 and 30 .

These polymers are deposited by spin coating. The well-known photolithography (365 nm) and RIE (Reactive Ion Etching) are used to perform these structures. However, photolithography step was improved in order to achieve sub-micron dimensions [7].

In order to achieve the tunability of the filter, gold electrodes are deposited. This requires a mask fabrication with electrodes pattern following the microring resonators design and with alignment marks. Note that the chromium pattern of the original mask was performed by a laser writing lithography KLOE's equipment. In a first step a film of gold is deposited by sputtering. Then a photolithography step permits to replicate the pattern and to align the electrodes on the rings. Finally gold is etched by using $\mathrm{KI} / \mathrm{I}_{2}$ in aqueous solution.

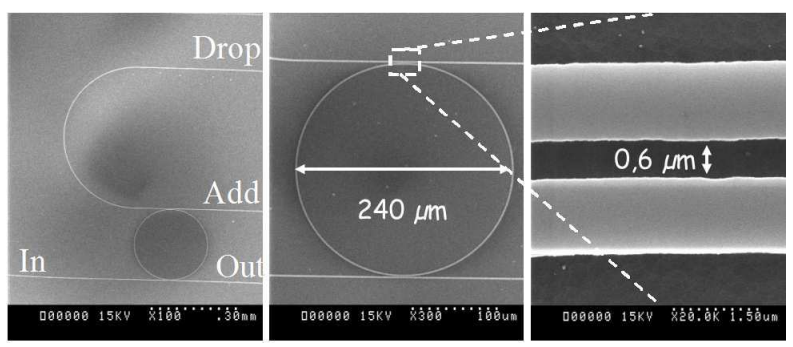

Figure 2: SEM image of polymer microring polymer ring and the gap, 
A schematic representation and a SEM picture of fabricated microring-resonators are given in Figure 1 and 2. In this study we chose to perform several series of micro-resonators with different gap sizes.

In order to validate our simulation results we measure the spectral response of microring resonators according to different gaps. A tunable laser (Agilent 8164A with 81680A tunable source) was injected in the input waveguide using a lensed fibre with a mode radius of $1.2 \mu \mathrm{m}$, at the output a standard single mode fibre is used to couple the output waveguide to the detector. This study aims to evaluate the filter properties taking into account the actual structure with the different deviations accumulated and caused by the fabrication process. The results show that the FSR is independent of the coupling ratio and its value is $1.98 \mathrm{~nm}$. Two important parameters of the filtering function for the application in a transmission system are the extinction ratio and the Full Width at Half Maximum (FWHM), the Figure 3 presents the changes of these parameters with the gap. First we see that the resolution limit of the lithography process is between 0.5 and $0.6 \mu \mathrm{m}$ as there is a large dispersion for the $0.5 \mu \mathrm{m}$ gap. In order to have an ER higher than $20 \mathrm{~dB}$ the gap must be equal or greater than $0.7 \mu \mathrm{m}$.

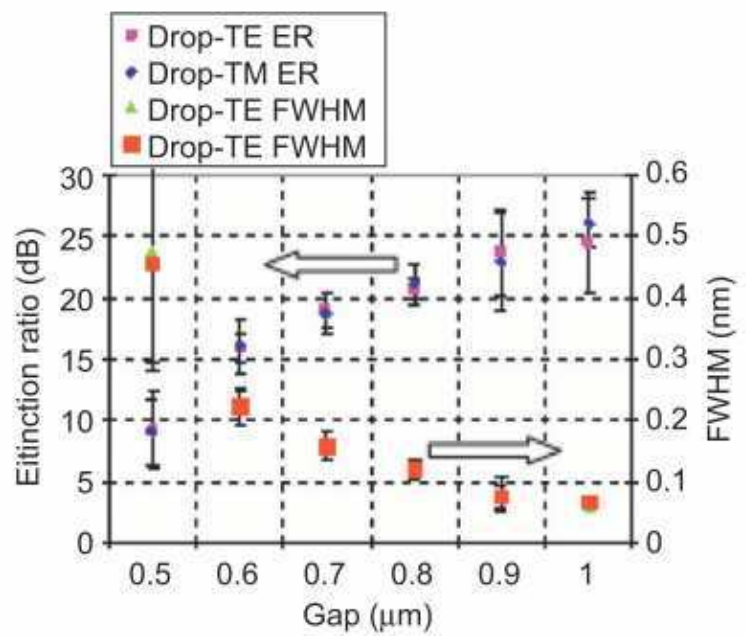

Figure 3: Extinction ratio and FWHM of drop port transfer.

\section{EXPERIMENTAL RESULTS}

The sample used for the measurement consists in a section of a wafer with several parallels micro-rings and a rectangular gold electrode that recover all the microrings (Figure 4). The length of the electrode is $23 \mathrm{~mm}$ and the width $250 \mu \mathrm{m}$, gold wires are bonded on each end.
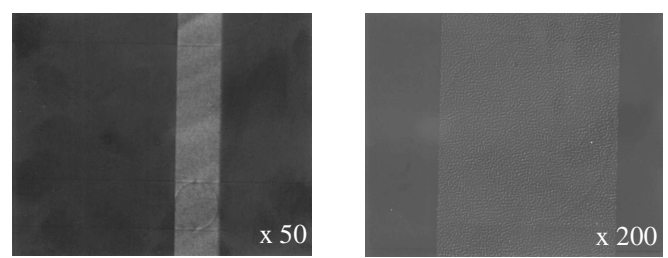

Figure 4: SEM image of gold rectangular electrodes on the rings. 
First of all to calibrate the electrode resistance according to temperature, the sample was inserted in a climatic chamber, and the resistance is measured at different temperature after stabilisation. The resistance change is linear: $\mathrm{R}(\mathrm{ohm})=82.235+0.133 \mathrm{~T}$ with $\mathrm{T}$ in degrees Celsius. This allowed determining the effective micro-ring temperature.

In a second step, the sample is assembled with a thermo-electric cooler (TEC), in order to control the sample temperature at a fixed temperature of $20^{\circ} \mathrm{C}$ independently of the environment. A current source is applied to the electrode and the voltage is measured in order to know the temperature and the electrical power supplied.

First the spectral responses of the micro-resonators are measured without power applied on the electrode. The result of TE polarization for a micro-resonator with a $0.7 \mu \mathrm{m}$ gap and a $120 \mu \mathrm{m}$ radius is shown on Figure 5. A theoretical curve obtained with a matrix model is also shown; it is according very well with the experimental response. The differences in the out of band ranges may be due to no perfect TE polarization state at the input fibre.

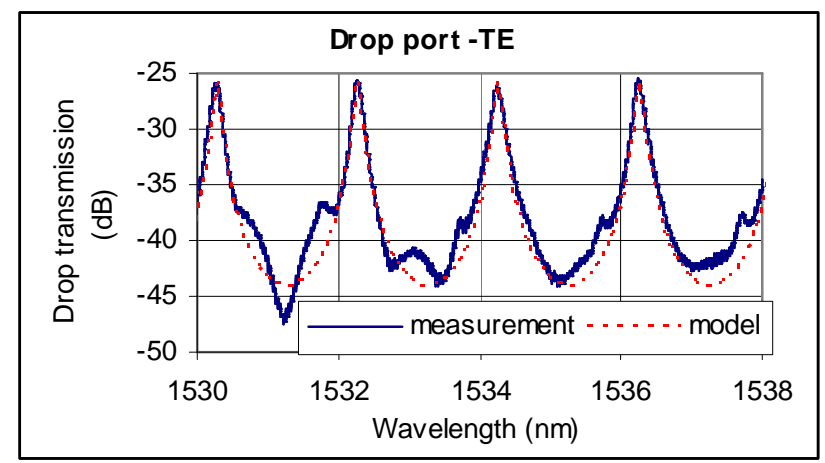

Figure 5: Experimental results of a $0.7 \mu \mathrm{m}$ gap micro-resonator, TE response at the drop port and theoretical response (dashed line).

Figure 6 shows the spectral response of a filter $(\mathrm{R}=120 \mu \mathrm{m}, \mathrm{g}=0.7 \mu \mathrm{m})$ according to the heating power applied to the electrode. Figure 5 shows the evolution of 4 resonant wavelengths according to the power applied to the electrode. On Figure 6(a) the curves show that the filter responses have the same shape at different heating powers. On Figure 6(b), the first sequence of measurements was done by increasing temperature and

(a)

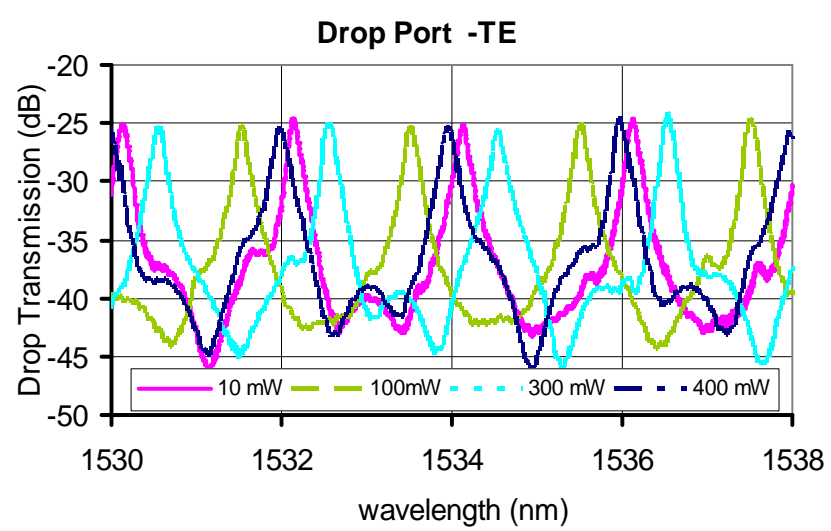

(b)

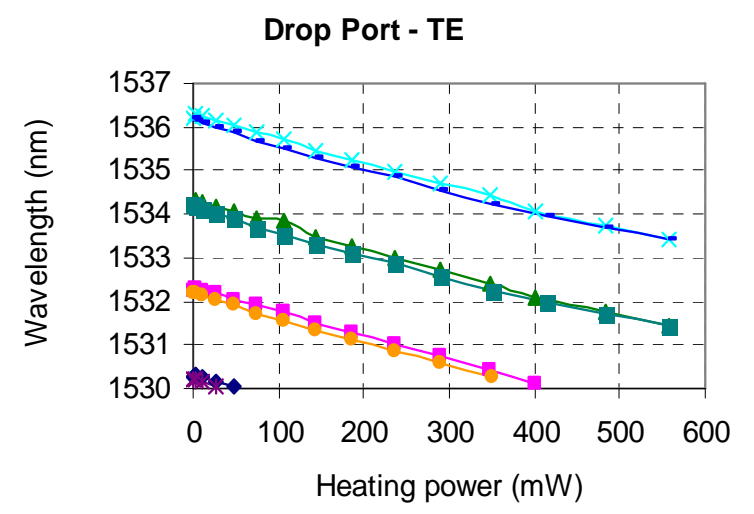

Figure 6: (a) Spectra of the drop port transmission for TE polarization with various heating power and (b) measured resonant wavelengths of four channels according to the heating power and the temperature.

then the second sequence was made by decreasing the temperature. We can note that in both directions, the resonant wavelengths follow the same curve, which shows the absence of hysteresis and excellent repeatability 
of the tunability. With this rectangular electrode, the resonant wavelengths change with the electrical power according to a coefficient value of $-0.0055 \mathrm{~nm} / \mathrm{mW}$ or $180 \mathrm{~mW} / \mathrm{nm}$. This high consumption level is due to the large volume of polymer heated under the electrode as the electrode surface is 5.5 square millimetres; if we consider only one microring the surface is $0.25 \mathrm{~mm}^{2}$ ( $1 \mathrm{~mm}$ length and $250 \mu \mathrm{m}$ width) and the tuning coefficient is $8.2 \mathrm{~mW} / \mathrm{nm}$. Considering the temperature deduced from the electrode resistance, a thermo optic coefficient is found to be $-0.15 \mathrm{~nm} /{ }^{\circ} \mathrm{C}$.

The next objective of the work will be to fabricate a heater electrode with a circular shape on the microring with an electrode width of $20 \mu \mathrm{m}$. From the design of the two types of electrodes and a thermal model of the polymer waveguides it is possible to evaluate what will be the power consumption with the ring localized electrode. The tuning efficiency for one micro-ring could be estimated around $2 \mathrm{~mW} / \mathrm{nm}$ and below $5 \mathrm{~mW}$ on the total range of the FSR.

\section{Conclusion}

We have fabricated integrated microring resonators with a couple of polymer PVCI/PMATRIFE as core and cladding waveguide materials. The filter design is calculated in the aim to perform a thermally tunable filter for telecommunication access network using WDM technology. We have determined the best trade-off between the characteristics of the filter (extinction ratio and FWHM) and the gap between ring and waveguides to meet the functional requirements of the tunable filter. We have achieved the fabrication of microring integrated circuits with these couple of polymers by a process we have developed, ensuring a wellcontrolled small gap size $(0.7 \mathrm{~mm})$. The micro-ring filters exhibit a good extinction ration up to $20 \mathrm{~dB}$. We have undertaken the first experiments of thermal tunability of the microring filter and we can report experimentally 5 $\mathrm{nm}$ shift of the dropped wavelength for a temperature change of $40 \mathrm{~K}$ with an excellent repeatability. The results reached with large gold electrodes on the micro-rings enable us to expect that the electrical consumption could be as low as a few $\mathrm{mW}$ with ring localized gold electrodes.

\section{Acknowledgment}

For theses works, the authors acknowledge supports from the ANR (Research French Agency), the Pôle Images@Réseaux in the project SELECTACESS and the support of the regional project, PONANT including FEDER funds.

\section{REFERENCES}

[1] P. Rabie, W.H. Steier, C.Z. Hang, L.R. Dalton, Journal of Lightwave Technology 20 (11) (2002) 1968.

[2] Lei Jin, Mingyu Li, Jian-Jun He, Optics Communications 284 (1) (2011) 156.

[3] A. Ramachandran, S. Wang, J. Clarke, S.J. Ja, D. Goad, L. Wald, E.M. Flood, E. Knobbe, J.V. Hryniewicz, S.T. Chu1, D. Gill, W. Chen, O. King, B.E. Little, Biosensors and Bioelectronics 23 (2008) 939.

[4] T. Ling, S.L. Chen, L.J. Guo, Optics Express 19 (2) (2011) 861.

[5] E.J. Klein, D.H. Geuzebroek, H. Kelderman, A. Driessen, Integrated optical add-drop multiplexer using thermally tunable microring resonators, IEEE/LEOS Benelux Chapter 2004 Annual Symposium, pp. 103-106, December 2-3 2004.

[6] Minming Geng, Lianxi Jia, Lei Zhang, Lin Yang, Ping Chen, Yuliang Liu, Optics Communications 282 (2009) 3477.

[7] A. Maalouf, M. Gadonna, D. Bosc, S. Lobo, L. Bramerie, Study of polymer micro-ring resonator based filter in system experiment at $10 \mathrm{Gbit} / \mathrm{s}$, in: ECIO'10, Proceedings, ref. WeP34 2010.

[8] A. Maalouf, M. Gadonna, D. Bosc, Journal of Physics D: Applied Physics 42 (1) (2009). (ref. 015106). 
